\title{
Stability Comparison of Quercetin and its Metal Complexes and their Biological Activity
}

\author{
Siva Mathiyalagan 1(D), Badal Kumar Mandal 1,*(D) \\ 1 Trace Elements Speciation Research Laboratory, Department of Chemistry, School of Advanced Sciences, Vellore \\ Institute of Technology, Vellore- 632014, India \\ * Correspondence: badalmandal@vit.ac.in;
}

Scopus Author ID 7102080708

Received: 6.06.2020; Revised: 1.07.2020; Accepted: 2.07.2020; Published: 5.07.2020

\begin{abstract}
Quercetin being an essential flavonoid, controls the metal flow in our body, and is an important dietary component in many daily foodstuffs. In this study, quercetin (QCT) metal complexes are synthesized, and their stability has been investigated in different $\mathrm{pH}$ conditions. Further, the oxidized forms of quercetin in the processed food products (garlic pickle) and in non-processed food (garlic) are examined. The quercetin metal complexes (M-QCT) and their oxidized derivatives are characterized by using UV-vis, FT-IR, UPLC-DAD, GC-MS, and AAS. The disintegration of QCT and M-QCT complexes is monitored by RP-UPLC with diode array (RP-UPLC-PDA) detection in detecting the loss of major components. Moreover, the present project has checked the exposure of $\mathrm{M}-\mathrm{QCT}(\mathrm{M}=\mathrm{Mg}$, $\mathrm{Zn}$ ) on the development/growth of zebrafish embryos. This study reveals that the Zn-QCT complex is more stable compare to std. QCT and Mg-QCT complex. Also, Zn-QCT is toxic to zebrafish embryos compared to std. QCT and Mg-QCT complex. The results of this study suggest the usage of M-QCT complexes in the processed foodstuffs instead of pure QCT.
\end{abstract}

Keywords: Quercetin metal complexes; stability; UPLC-PDA; garlic pickle; zebrafish embryos.

(C) 2020 by the authors. This article is an open-access article distributed under the terms and conditions of the Creative Commons Attribution (CC BY) license (https://creativecommons.org/licenses/by/4.0/).

\section{Introduction}

Quercetin (QCT) $\left(\mathrm{C}_{15} \mathrm{H}_{10} \mathrm{O}_{7}\right)$ is a widely abundant flavonoid available in many fruits and vegetables of human diets. In plants, it is generally associated with ethers, sugars, and phenolic acids. A few studies have estimated intake of QCT as $20-50 \mathrm{mg} /$ day via the diets [1, 2]. These flavonoids are denoted as vitamin $P$, which also acts as antioxidants and is known to control the bioavailability of metals in the human body system. Different forms of QCT analogs could modify their rate of absorption in the stomach [3]. The forms of its analogs and contents play a major role in their absorption [4]. Its basic structure is 2-phenyl-benzo-pyrones with different substituents in both benzene rings of the basic structure available in nature. Differences in heterocyclic rings give rise to 4000 different flavanones, flavonols, anthocyanidins, catechins, flavones, and isoflavones in the literature. Quercetin (QCT), having high therapeutic efficacy, plays an efficient active pharmaceutical ingredient (API) in the medical industry. Chen \& Kang (2005) [5] reported an ingredient in many food and pharmaceutical industries due to its antioxidant activity, followed by an anticancer activity. Practically, the major problem of QCT uses in different essential applications is its stability during food processing and storage (FPS), leading to loss of original QCT, which depends on processing temperature, matrix $\mathrm{pH}$, incorporated metal ions, and glutathione (GSH). Moreover, other factors such as stability, solubility, and biological half-life of QCT in consumable 
products control its efficacy. The degradation pathway of QCT is shown in Fig. 1a and the stability of QCT and M-QCT complexes has been extensively examined by monitoring its chemical changes during FPS. The QCT content was reduced due to oxidation and degradation during FPS [6]. Hence, the stability of QCT may be influenced by metal ions, $\mathrm{pH}$, temperature, and glutathione (GSH) in different food matrixes [7-9]. Moreover, QCT has low chemical stability, water-solubility, short biological half-life, and less bioavailability affecting its efficacy in food processing and pharmaceutical industries [10]. QCT is less soluble in ethanol $(2.0 \mathrm{mg} / \mathrm{mL})$ at $37^{\circ} \mathrm{C}$ and completely soluble in DMSO $\left(150 \mathrm{mg} / \mathrm{mL}, 25^{\circ} \mathrm{C}\right)$ [11]. Its water solubility is very less $\left(0.01 \mathrm{mg} / \mathrm{mL}\right.$ at $\left.25^{\circ} \mathrm{C}\right)$ [12], which becomes a challenging task to increase the level of QCT in most of the food matrixes. Generally, the delivery systems look for a novel efficient encapsulation system to increase the number of functional components in foodstuffs by protecting them against oxidation and degradation during FPS. In addition, the compound incorporated can be selectively distributed to the particular site of action at a controlled rate [13, 14]. Different delivery systems, i.e., polymeric nanoparticles (NPs) [15, 16], liposomes $[17,18]$, microparticles, and emulsions [18], have considerably improved the therapeutic value of many bioactive compounds by increasing their bioavailability. Hence, the mode of delivery systems may restrict the degradation of the bioactive compounds due to exposure of heat, light, and metabolic enzymes by increasing their stability $[19,20]$. On the other hand, these approaches also have some disadvantages like high manufacturing cost, difficult scaling up, and laborious evaluation for improved applications [21-25].

Among many flavonoids, flavones can chelate efficiently with divalent metals like $\mathrm{Fe}^{+2}$, $\mathrm{Al}^{+2}, \mathrm{Zn}^{+2}$, and $\mathrm{Cu}^{+2}$. Metal complex formation with QCT plays an important role in biological systems, and also provides sensitive color stabilization in higher plants. The flavone's interaction with metal ions could modify the antioxidant properties and the stability of flavonoids. The presence of metal ions in the QCT molecule influences its biological activities. Generally, QCT chelates with metal ions through its structural hydroxy and oxo-groups. Due to its biotic and medical activities, it exists in several foods such as apple, tea, onion, nuts, berries, cauliflower, and cabbage. The main objective of the study is to examine the stability of QCT, M-QCT (M =Mg, Zn) complexes, and the amount of QCT in processed food samples to evaluate its stability during FPS.

\section{Materials and Methods}

All reagents were of superior grade. HPLC grade methanol, QCT.2 $\mathrm{H}_{2} \mathrm{O}$ [2-(3,4dihydroxyphenyl)-3,5,7-trihydroxy-4H-1-benzopyran-4one)] and $\mathrm{MgSO}_{4}$ were procured from Sigma-Aldrich (Bangalore, India).

\subsection{Sample collection and extraction.}

The processed and preserved QCT rich garlic pickles and fresh garlic were collected from the Vellore market (Tamilnadu, India) and studied. The extraction of QCT was performed from the $10 \mathrm{~g}$ garlic pickles as well as fresh garlic after warming in $10 \mathrm{~mL}$ hot water with 25 $\mathrm{mL}$ ethanol. Then, the fat contents were removed using $50 \mathrm{~mL}$ hexane [26, 27]. Afterward, the sample $\mathrm{pH}$ was adjusted to 6.8 using disodium hydrogen phosphates and sonicated at ambient temperature for $30 \mathrm{~min}$, and the organic layer was separated after shaking using a $250 \mathrm{~mL}$ separating funnel. Finally, the aqueous layer was centrifuged at $4500 \times \mathrm{g}$ for $5 \mathrm{~min}$, and the process was repeated thrice until the resulting extract was colorless [28]. The colorless solution 
was vacuum dried, and QCT was isolated using semi-preparative HPLC followed by characterization using UV-Vis, FT-IR, NMR, GC-MS, LC-MS, and UPLC-PDA. Further, the content of QCT in food samples was quantified using the UPLC-PDA method.

\subsection{Fourier Transform Infrared Analysis (FTIR).}

The existing functional groups in both QCT and the synthesized M-QCT complexes were detected using JASCO FT-IR 4100 (Shimadzu IR AFFINITY-1) in DRS mode within the range of $4000-400 \mathrm{~cm}^{-1}$ at a resolution of $4 \mathrm{~cm}^{-1}$.

\subsection{Chromatographic analysis by UPLC-PDA method.}

The stability experiments were performed on QCT and M-QCT $(\mathrm{M}=\mathrm{Zn}, \mathrm{Mg})$ using the UPLC-PDA method. The separation was done using UPLC equipped with a Quaternary pump, autosampler, and PDA-E-LAMBDA detector fitted with Acquity UPLC BEH C 18 $(150 \mathrm{~mm} \times 2.1 \mathrm{~mm}$ i.d., $130 \AA, 1.7 \mu \mathrm{m})$ analytical column. The mobile phase methanol and acetonitrile $(1: 1 \mathrm{v} / \mathrm{v})$ mixture with $\mathrm{pH} 6.8$ was adjusted with dilute hydrochloric acid. The samples were analyzed using the mobile phase at a flow rate of $0.3 \mathrm{~mL} / \mathrm{min}$ at $37^{\circ} \mathrm{C}$, but ethanolic samples were used for UV-vis analysis. M-QCT components and other degraded products were analyzed by chromatography with the respective standard solutions, and also the electronic absorption spectra attained from in-line diode array detection were compared with the major M-QCT derivatives by the previously published electronic absorption spectra [29]. The changes in QCT molecules and M-QCT complexes due to $\mathrm{pH}$ effects were monitored by the chromatograms of the PAD signals. Empower 3 software was used for instrument control, data acquisition, and analysis.

\subsection{Preparation of standard solutions.}

Standard QCT was dissolved in methanol to obtain a concentration of $1000 \mu \mathrm{g}$ QCT/1mL MeOH. Then, different concentrations of QCT solution $(0.05,0.5,1,2,5,10,25$, 50,100 and $200 \mu \mathrm{g} / \mathrm{mL}$ ) were prepared from $1000 \mu \mathrm{g}$ QCT/1mL MeOH stock solution using UPLC mobile phase.

\subsection{Synthesis of Quercetin Metal (Zn, Mg) complex.}

The solid QCT (170 mg/20 mL HPLC grade methanol; 0.01M) was stirred with a magnetic stirrer until the QCT completely dissolved in a $100 \mathrm{~mL}$ beaker. About $50 \mathrm{~mL}$ methanolic $\mathrm{NaOH}$ was added to the yellow-colored solution for the deprotonation of the ligand. The solution $\mathrm{pH}$ was adjusted to 6 by adding $1.0 \mathrm{M} \mathrm{H}_{2} \mathrm{SO}_{4}$. Then, $0.225 \mathrm{~g}$ magnesium sulfate $(0.02 \mathrm{M})$ was added to the flask until the color of the solution transformed to dark yellow, and further, the solution was stirred for $1.5 \mathrm{~h}$ more at room temperature and filtered. The filtrate was slowly evaporated to a dark yellow product at room temperature and finally washed with methanol followed by vacuum drying, which yielded the yellowish-brown product. Similarly, the Zn metal complex was also prepared (Fig. 1b) [27-32]. The products were characterized by using UV-vis spectroscopy, IR spectroscopy, AAS, GC-MS, and UPLC-PDA method. 


\subsection{Zebrafish maintenance.}

The AB strain (wild-type) of zebrafish was grown on a circulating aquarium system for zebrafish study in an environmentally controlled room temperature of $28^{\circ} \mathrm{C}$ and $80 \%$ humidity. The fishes breeding were prompted by keeping females and males in a 1:3 ratio. The photoperiods were maintained by keeping $10 \mathrm{~h}$ in darkness and $14 \mathrm{~h}$ under the light. The water temperature was maintained at $26^{\circ} \mathrm{C}$. The adult zebrafish were feeding with bloodworms at regular and reproductive times. The larva zebrafish were fed with $10 \mathrm{~mL}$ saline water mixed with $2 \mathrm{~mL}$ egg yolk daily. The fertilized eggs were taken and examined under a stereomicroscope (Olympus SZX10, Tokyo, Japan) within 4 h post-fertilization (hpf) to study their quality. All embryos were collected from the same spawns of eggs to compare between treated and control groups. The collected healthy embryos were filed in 6 well culture plates (10 embryos in $2 \mathrm{~mL}$ solution/well). At all steps, the maturing larvae and embryos were maintained at $26^{\circ} \mathrm{C}$ in $\mathrm{E} 3$ medium (pH 7.2, constituents as $0.33 \mathrm{mM} \mathrm{MgSO}_{4}, 0.17 \mathrm{mM} \mathrm{KCl}$, $0.33 \mathrm{mM} \mathrm{CaCl}_{2}$, and $5 \mathrm{mM} \mathrm{NaCl}$ ). Newly fertilized embryos were treated with different concentrations of Zn-QCT and Mg-QCT (25, 50, 100, and $200 \mathrm{mg} / \mathrm{L}$ ) for 24 to $96 \mathrm{hpf}$. Spawns fertilized eggs (fertilization rate $>90 \%$ ) were used in this study throughout.

\subsection{Treatment with varying $\mathrm{pH}$.}

The effect of acidic $\mathrm{pH}$ on the stability of QCT and M-QCT derivatives was studied in buffered solutions of $\mathrm{pH}$ 2.0, 3.0, 4.0, 6.0, and 7.5. The buffered solutions were prepared by mixing $0.1 \mathrm{M}$ citric acid and $0.1 \mathrm{M}$ ammonium acetate to the required $\mathrm{pH} \pm 0.05$.

\subsection{UV-Vis Spectrophotometry.}

Absorption spectra of QCT in ethanol medium were studied using the AU-2603 UVVis double beam spectrophotometer equipped with $3.0 \mathrm{~cm}$ quartz cells. All spectra were taken within 200 to $800 \mathrm{~nm}$ of $\lambda_{\max }$ throughout the study.

\section{Results and Discussion}

\subsection{Results.}

Quercetin contains hydroxyl, carbonyl, and ether groups in its structure. Generally, phenols display two absorption bands in the range of 200 to $380 \mathrm{~nm}$. The peak appeared at the shorter wavelength denoted as the B-band and the one at longer wavelength denoted as C-band. These peaks were observed at longer wavelengths for phenols when dissolved in sodium hydroxide solution. The extinction coefficients and absorption spectra of phenols depend on the nature of the solvent, intra- and inter-molecular H-bonding, steric effects, electronwithdrawing, and donating substituents in the benzene ring. This study has validated the changes in QCT and M-QCT structures due to acid exposure by monitoring phenol related changes in their absorption spectra. The absorption spectrum of QCT in methanol solution shows an absorption band at $376 \mathrm{~nm}$ corresponding to $\mathrm{n}-\pi^{*}$ and at $260 \mathrm{~nm}$ to $\pi-\pi^{*}$ transition $[33,34]$. Fig. 2 represents the UV-Vis spectra of QCR and M-QCR $(\mathrm{M}=\mathrm{Mg}, \mathrm{Zn})$ derivatives. The transition of the absorption band at $376 \mathrm{~nm}$ is seen for the M-QCT complex indicating its redshift.

The binding sites and the coordination properties of M-QCT complexes were examined by the FT-IR study. The main peaks with the necessary evidence can be acquired by assessing 
the IR spectra of M-QCT complexes. The $\mathrm{C}=\mathrm{O}$ stretching vibration frequency of std QCT arises at $1662 \mathrm{~cm}^{-1}$, and after complex formation, it has been shifted to $1653 \mathrm{~cm}^{-1}$.

This shift proves metal coordination with carbonyl oxygen electrons [35, 36]. During the interaction of QCT and metal ions, the bond order of different bonds such as C-O and 3$\mathrm{OH}$ could change. The appearance of new peaks at 1541 and $1373 \mathrm{~cm}^{-1}$ could be linked to the symmetric and antisymmetric stretching vibration modes of the $\mathrm{C}-\mathrm{O}$ group at the binding sites suggesting complex formation. The peaks at 1662 and $1274 \mathrm{~cm}^{-1}$ correspond to $\mathrm{C}=\mathrm{C}$ and $\mathrm{C}-\mathrm{O}-$ $\mathrm{C}$ bond stretching, which have slightly shifted due to the formation of the metal complex. The deformation mode of C-O-H observed at $1328 \mathrm{~cm}^{-1}$ in the ligand (Fig. 3a) is shifted to 1373 $\mathrm{cm}^{-1}$ in the complex (Fig. 3b), which represents an increase in bond order suggesting metal coordination with the O-phenolic O-H group of QCT in the complex. Also, the appearance of M-O stretching vibration at $465 \mathrm{~cm}^{-1}$ suggests the metal complex formation. At the same time, the pure ligand shows no such vibrational peak. The aqueous -OH bands of the complex appear at $3325 \mathrm{~cm}^{-1}$ (Fig. 3b), revealing the presence of water crystallization in the complex [37]. The synthesized M-QCT complexes were characterized using gas chromatography-mass spectroscopy (GC-MS). Fig. S1, and Fig. S2 shows the GC-MS spectra of Zn-QCT (326.2489 $\mathrm{m} / \mathrm{z})$ and $\mathrm{Mg}-\mathrm{QCT}(357.5280 \mathrm{~m} / \mathrm{z})$, respectively.

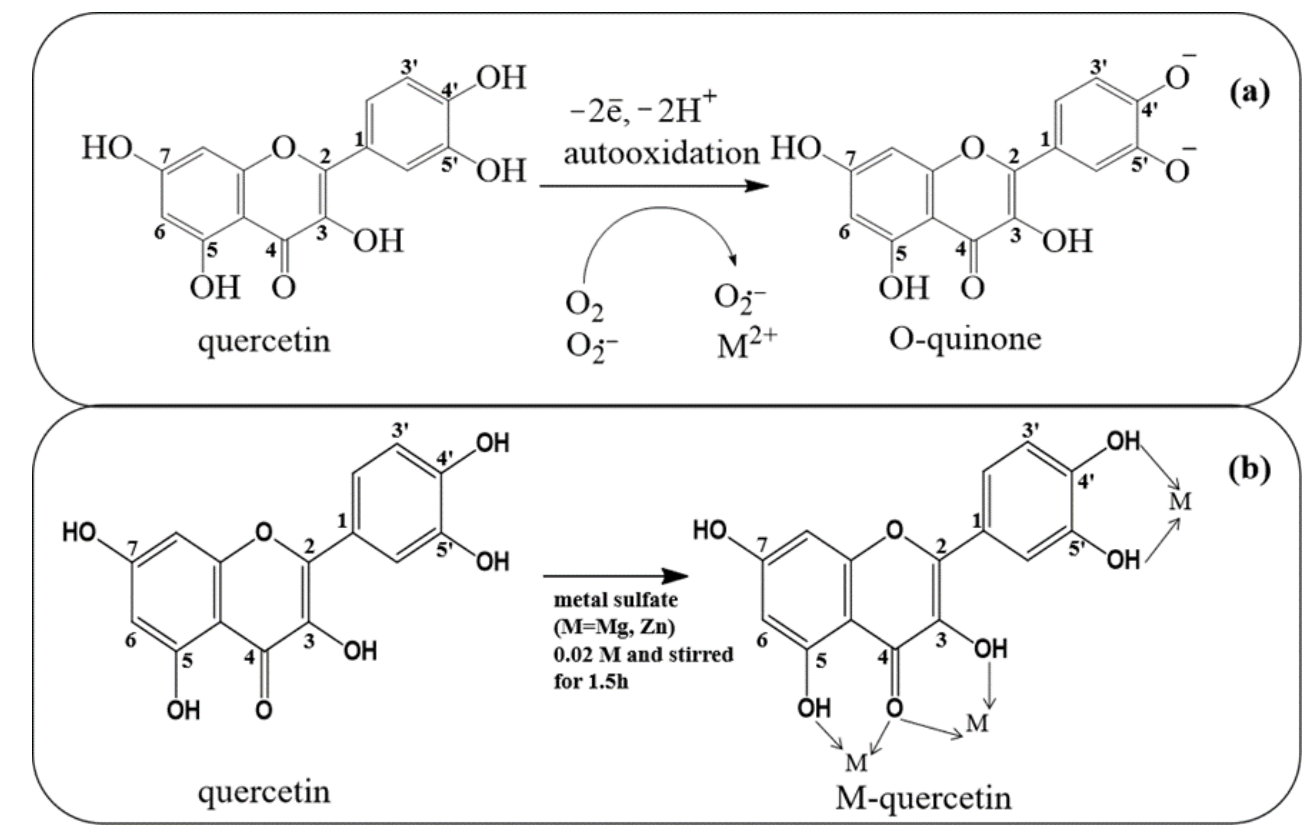

Figure 1. Auto Oxidation of QCT (a) and the possible chelating sites of QCT (b).

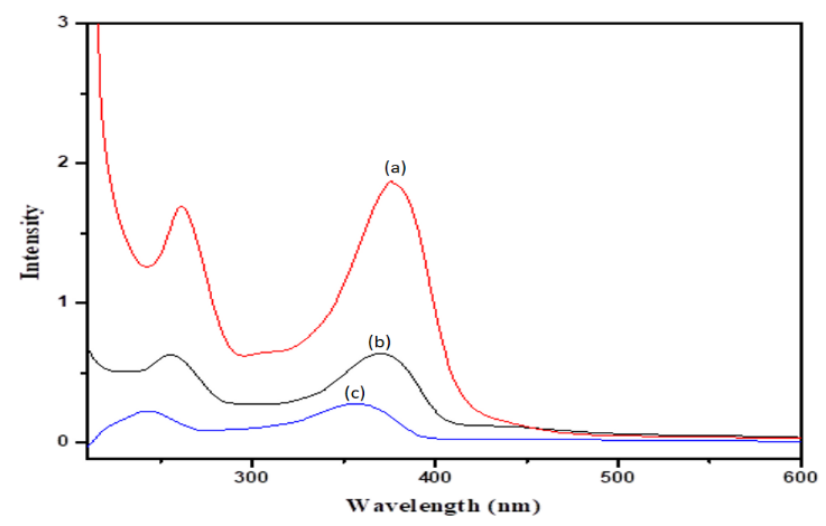

Figure 2. UV-Vis spectra of QCT (a), Mg-QCT (b), and Zn-QCT (c). 


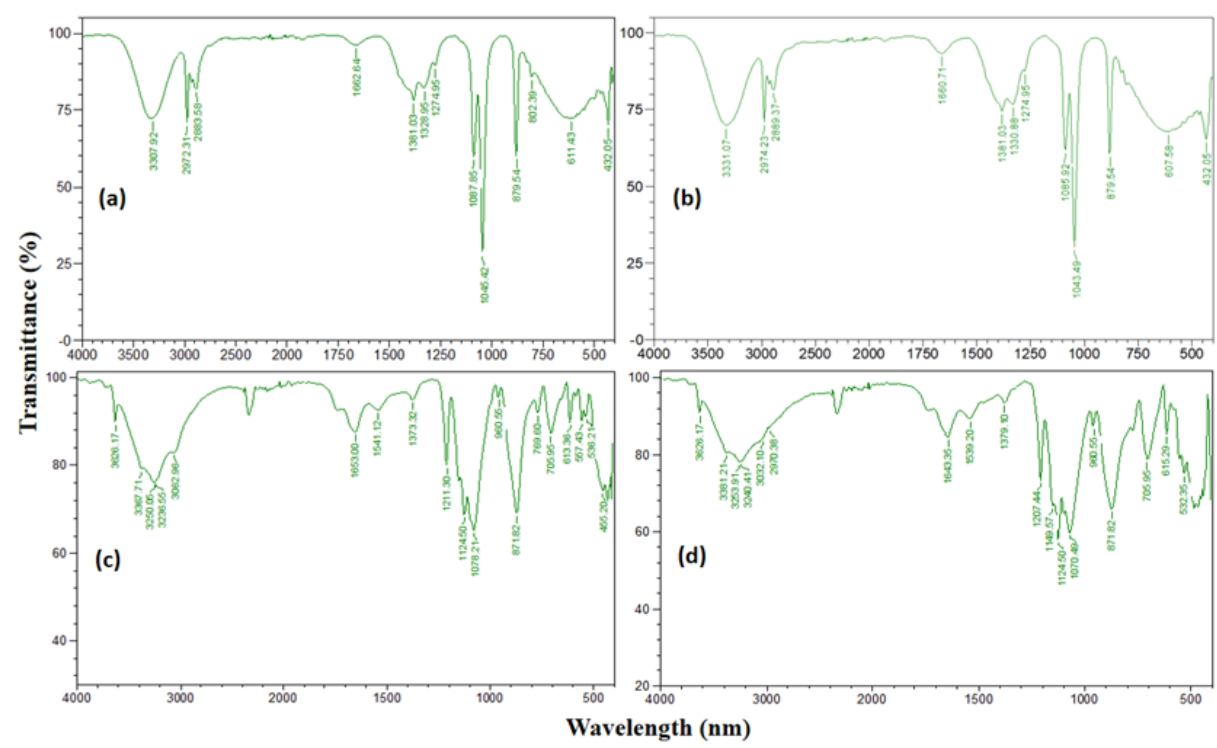

Figure 3. FTIR Spectra of QCT (a), QCT-Quinone (b), Mg-QCT (c), Zn-QCT (d).

The contents of QCT, Zn-QCT, and Mg-QCT were determined by the UPLC-PDA method after keeping their ethanolic solutions at different $\mathrm{pH}$ ranging from $\mathrm{pH} 2$ to $\mathrm{pH} 6.8$ (Table 1). The UPLC-PDA method supports additional evidence on the reproducibility of the spectral absorption measurements and the stabilities of the test M-QCT derivatives. Being a typical study that could become a benchmark for future revisions with other metal complexes of phenolic derivatives, we have provided the following detailed explanations of the detected changes in M-QCT derivatives as a result of $\mathrm{pH}$ variation by UPLC-PDA method. The formation of M-QCT complexes has been extensively reported in this study.
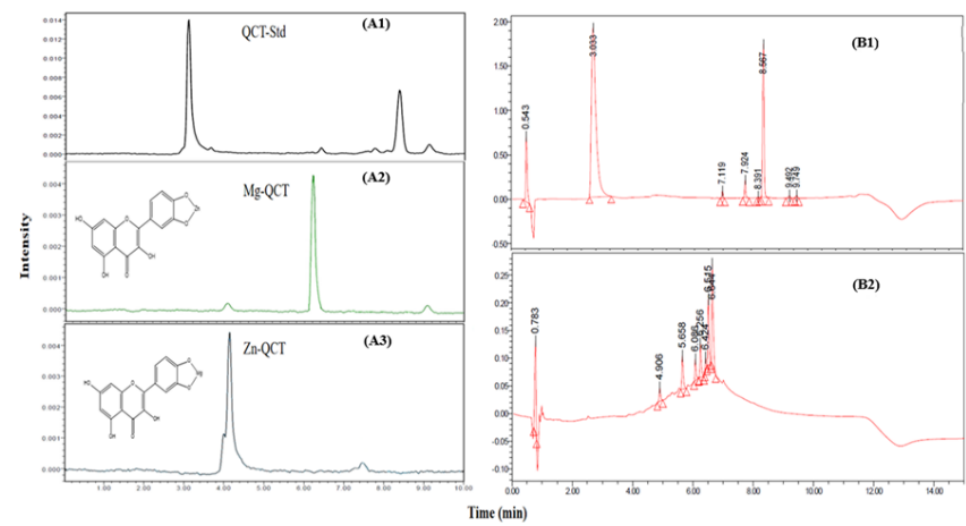

Figure 4. UPLC-DAD chromatogram of QCT std (A1), Mg-QCT (A2), Zn-QCT (A3), and the chromatograms of non-processed Garlic (B1) and processed Garlic pickle (B2).

Fig $1 \mathrm{~b}$ illustrates the complexion sites at the positions of $\mathrm{O} 3 / \mathrm{O} 4, \mathrm{O} 4 / \mathrm{O} 5$, and $\mathrm{O} 3$ '/O4'. In the present study determination of QCT, i.e., the quantitation was done by matching retention time (RT) of QCT peak (RT as $3.16 \mathrm{~min}$ ) with M-QCT (RT as $3.2 \mathrm{~min}$ ) (Fig. 4 A1, A2, and A3). No interference was observed because no other peak appeared at the same RT of QCT, which assures a quick quantitation of the QCT content in many food samples. This separation technique can also study the shelf-life of QCT in several samples under storage at varying temperature and $\mathrm{pH}$. The QCT content at $\mathrm{pH} 2.0$ degraded to $79.21 \%$ at room temperature (Table 1, Fig. 5). Consequently, in order to assure the stability of the M-QCT complex during storage, it could be kept at gastric $\mathrm{pH}$ for prolonged shelf-life [38]. In addition, we analyzed real samples (i.e., fresh garlic and garlic pickle) collected from the local market. 
The QCT content was $18.26 \mathrm{mg} / \mathrm{kg}$ in fresh garlic and the processed garlic pickle as 1.04 $\mathrm{mg} / \mathrm{kg}$. Moreover, our analysis results suggest that no oxidative products of QCT were found in fresh garlic samples, but the concentration of the oxidative product QCT-Quinone in the processed garlic pickle was $7.2 \mathrm{mg} / \mathrm{kg}$ (Fig.4 B1 and B2) [39, 9].

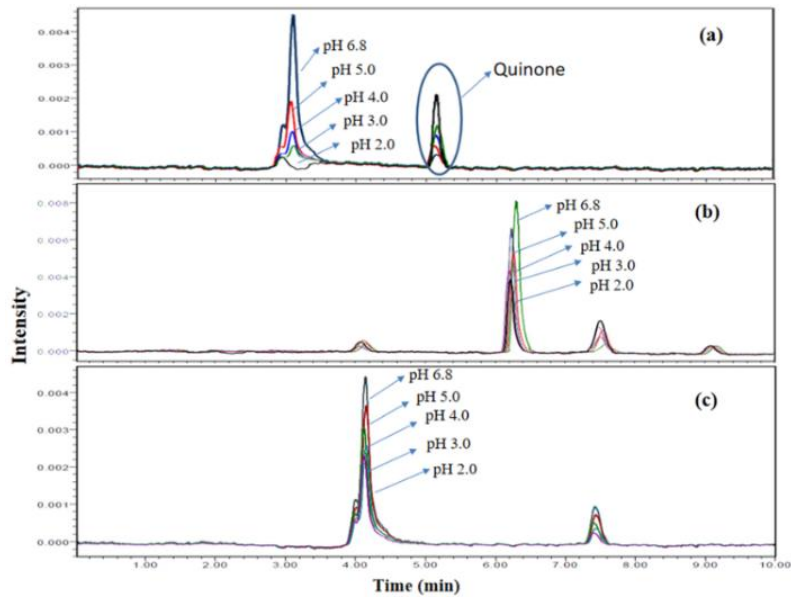

Figure 5. UPLC-PDA chromatograms of (a) std. QCT, (b) Mg-QCT, and (c) Zn-QCT complex during stability study in acidic condition.

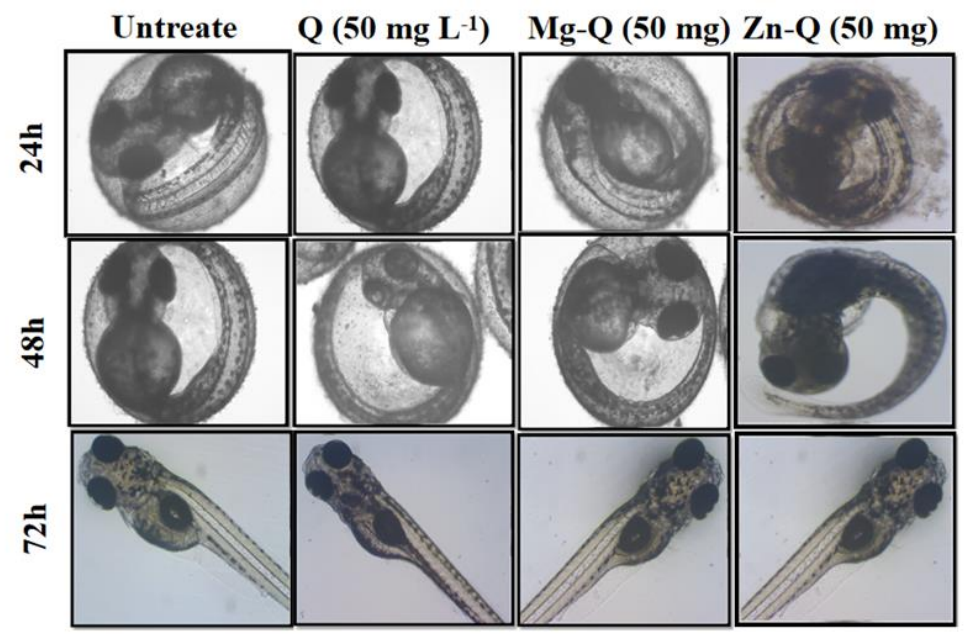

Figure 6. Lethality of M-Quercetin Exposure to Zebrafish Embryos.

\subsection{Discussion.}

The effect of metals like $\mathrm{Zn}$ and $\mathrm{Mg}$ incorporation on QCT structure was chosen as a model system and investigated any variation in the structure and properties of these flavonoid complexes. UPLC-PDA method can identify and quantify the formation of metal-QCT complexes efficiently. In this study, $\mathrm{Mg}(\mathrm{II})$ and $\mathrm{Zn}(\mathrm{II})$ complexes of QCT have been successfully synthesized (Fig. 1b) and characterized by UV-Vis, FT-IR, GC-MS, and UPLCPDA method. Normally, QCT undergoes chemical changes during FPS, which is a tool to investigate its stability. The content of QCT was significantly reduced due to degradation and oxidation at the time of food processing and storage. The presence of metal ions, $\mathrm{pH}$, and high temperature affect the stability of QCT in various foodstuffs and also other compounds [40]. Figure 5 shows the UPLC-PDA spectra of the standard QCT and M-QCT complexes under different acidic $\mathrm{pH}$, which were kept to evaluate their stability. 
Table 1. Stability of Standard Quercetin (QCT) and M-QNPs $(\mathrm{M}=\mathrm{Mg}, \mathrm{Zn})$ in ethanol at different $\mathrm{pH}$ by

\begin{tabular}{c|c|c|c|c}
\multirow{2}{*}{ S. No } & \multirow{2}{*}{$\mathbf{p H}$} & \multirow{2}{*}{ QCT } & \multicolumn{2}{c}{ Degradation (\%) } \\
\cline { 4 - 5 } & & & $\mathbf{Z n - Q}$ & $\mathbf{M g - Q}$ \\
\hline 1 & 6.8 & 0.43 & 0.95 & 0.28 \\
\hline 2 & 5 & 44.8 & 13.74 & 32.55 \\
\hline 3 & 4 & 56.42 & 22.06 & 38.21 \\
\hline 4 & 3 & 70.45 & 34.95 & 43.06 \\
\hline 5 & 2 & 79.21 & 55.3 & 48.93
\end{tabular}

Before quantitation of QCT and M-QCT content in the collected real samples, the developed UPLC-PDA method was validated by calculating the limit of detection (LOD), the limit of quantitation (LOQ), signal-to-noise $(\mathrm{S} / \mathrm{N})$ ratio, precision, and recovery. The calibration graph was plotted by using four analytical standard samples $(10,30,50$, and 100 $\mu \mathrm{g} / \mathrm{L}$ ) after triplicate injections of each standard (Fig. S3). LOD and LOQ were calculated by multiplying 3.3 and 10 times of $\mathrm{S} / \mathrm{N}$ ratio estimated through regression lines (Table. 4). This chromatographic method allows detection of QCT and M-QCT in less than $5 \mathrm{~min}$, and hence it can be used to examine a large number of samples quickly. LOD of the std. QCT is 4.52 $\mu \mathrm{g} / \mathrm{L}$, and LOQ of QCT is $13.71 \mu \mathrm{g} / \mathrm{L}$. The recovery results reveal significantly high recovery values $(101.38 \%)$ using the UPLC-PDA method with RSD values of $2.90 \%$ (data not shown). The inter-day precision was assessed by injecting two replicate samples in two different days, and the data were used to calculate reproducibility and repeatability of the applied chromatographic method.

The stability of QCT is influenced by acidic $\mathrm{pH}$. The aqueous QCT degrades in acidic medium resulting instability i.e., loss of original content due to oxidation, hydroxylation, and ring-cleavage. It obviously shows that the Mg-QCT solution was disintegrated up to $48.93 \%$ and Zn-QCT to 55.30\% compared to that of std. QCT solution (79.21\%) at $\mathrm{pH} 2.0$. Moreover, Mg-QCT was stable up to $99.72 \%$, and $\mathrm{Zn}$-QCT was stable up to $99.05 \%$ compared to that of std. QCT solution (99.57\%) at pH 6.8 (Fig. 5 and Table 1). Hence, the M-QCT complexes show higher solubility than QCT during processing and storage at lower $\mathrm{pH}$ i.e., acidic conditions.

We also checked the toxicity of QCT or M-QCT on zebrafish embryos in vitro. Kimmel et al. (2019) [28] reported that normal zebrafish embryos hatching occurred at $72 \mathrm{hpf}$. Hatching rates were delayed after exposure to 100 , and $200 \mathrm{mg} / \mathrm{L} \mathrm{Zn-QCT} \mathrm{and} \mathrm{Mg-QCT} \mathrm{compare} \mathrm{to} \mathrm{the}$ non-exposure group within $96 \mathrm{~h}$ of exposure (Fig. 6). This hatching time delay was detected in a dose of QCT and a time-dependent model. Mg-QCT based inhibition of hatching could be an outcome of the hindrance of $\mathrm{Mg}$ and $\mathrm{Zn}$ ions with the hatching enzyme Chorionase of fish [41]. Bai et al. (2010) [42] also established the suppression of hatching with $\mathrm{Cu}$ ions exposure. As a sign of this hatching obstruction by incorporated metal ions in the QCT structure, the regular growth of embryos was distressed. Results from our study have displayed both axial and nonaxial defects, which were severe with increased doses of Mg-QCT (200 mg/L). Lee et al. (2012) reported tail defects when embryos were exposed to Ag-NPs, which are very similar to our study results [43]. In the present study, Zn-QCT showed higher toxicity to the zebrafish embryo compare to Mg-QCT and std. QCT. This toxicity is mainly attributable to M-QCT complexes and their soluble ions (Table 2).

Table 2. Lethality of Quercetin Exposure to Zebrafish Embryos.

\begin{tabular}{c|c} 
Compounds & Lethality exposure to zebrafish in ppm \\
\hline Quercetin & 200 \\
\hline Zn-Quercetin & 138 \\
\hline Mg-Quercetin & 145
\end{tabular}


QCT was oxidized to different oxidation products, i.e., QCT-Quinones (Fig. 1). The effects of storage, $\mathrm{pH}$, and heat treatment of QCT in food are listed in Table 3. About $17 \%$ of QCT in grapefruit juice was reduced during pasteurization at $80^{\circ} \mathrm{C}$ for $91 \mathrm{sec}$ [48]. In addition, storage time also influenced the stability of QCT. Price et al. (1997) [44] reported a 100\% loss of QCT in onion (Allium cepa) after storage at $4^{\circ} \mathrm{C}$ in the dark for 24 weeks, whereas $46.1 \%$ loss of QCT in strawberry juice was reported after storage in the dark for 56 days at $4^{\circ} \mathrm{C}$. In another study, a $40 \%$ loss of QCT conjugate in the raspberry jam was noticed after storage for 180 days in the dark at $20^{\circ} \mathrm{C}$.

As the QCT stability is both temperature and $\mathrm{pH}$-dependent, QCT is highly unstable in organic solutions like methanol at $\mathrm{pH}>7$. Previous studies reveal that the degradation of QCT was more in the alkaline medium [7,9]. However, in this study, we have analyzed QCT quality by identifying its oxidative products present in processed food under moderate $\mathrm{pH}$ and temperature, and the results suggest the presence of the oxidative product of QCT in processed food. Therefore, relatively stable M-QCT complexes can be used in processed foods, which are essential flavonoids in foodstuffs.

Table 3. The effects of storage, $\mathrm{pH}$, and heat treatment of QCT in food products.

\begin{tabular}{|c|c|c|c|c|}
\hline S.No & Food Product & Processing condition & $\%$ of Degradation & Reference \\
\hline 1 & Beverages & $\begin{array}{l}\text { Treatment with various } \mathrm{pH} \text { values } \\
\text { like } \mathrm{pH} 2.7,7 \text { and } 10 \text {, for } 96 \mathrm{~h}\end{array}$ & $\begin{array}{c}100 \% \text { degradation of QCT } \\
\text { after } 120 \text { min at } \\
\text { pH } 10\end{array}$ & [9] \\
\hline 2 & Beverages & $\begin{array}{l}\text { Treatment with different } \mathrm{pH} \text { values } \\
\text { ( } \mathrm{pH} 1 / 45 \text { and } 8 \text { ) with air or nitrogen } \\
\text { perfusion for } 300 \mathrm{~min}\end{array}$ & $\begin{array}{l}100 \% \text { degradation of QCT } \\
\text { after } 180 \text { min at } \\
\text { pH 8; The presence of oxygen- } \\
\text { enhanced the degradation } \\
\text { of quercetin }\end{array}$ & [7] \\
\hline 3 & $\begin{array}{l}\text { Bean (Phaseolus } \\
\text { vulgaris L.) }\end{array}$ & $\begin{array}{c}\text { Atmospheric and pressure } \\
\text { boiling }\left(121^{\circ} \mathrm{C}\right) \text { with and without } \\
\text { soaking }\end{array}$ & 70\% degradation of QCT & [45] \\
\hline 4 & Onion bulbs & $\begin{array}{l}\text { Atmospheric boiling }\left(100^{\circ} \mathrm{C}\right) \text { for } \\
60 \mathrm{~min}\end{array}$ & $43.2 \%$ degradation of QCT & [46] \\
\hline 5 & Beverages & Heating at $97^{\circ} \mathrm{C}$ for $240 \mathrm{~min}, \mathrm{pH} 8$ & $\begin{array}{c}100 \% \text { degradation of } \\
\text { QCT due to the presence of } \\
\text { oxygen, while the degradation } \\
\text { without oxygen } \\
\text { was only } 15 \%\end{array}$ & [47] \\
\hline 6 & Grapefruit juices & $\begin{array}{c}\text { Conventional thermal } \\
\text { pasteurization } \\
\text { heating at } 80^{\circ} \mathrm{C} \text { for } 91 \mathrm{~s}\end{array}$ & $17 \%$ degradation of QCT & [48] \\
\hline 7 & Beverages & $\begin{array}{c}\text { Quercetin and } \mathrm{CuCl}_{2} \text { solutions } \\
\text { mixed in } \\
\text { three ratios }(0.5,1 \text { and } 2)\end{array}$ & $\begin{array}{l}40 \% \text { degradation of QCT 3- } \\
\text { glycoside }\end{array}$ & [49] \\
\hline 8 & Onions (Allium cepa) & $\begin{array}{c}\text { Long-term storage (168 days, } 20 \\
\left.{ }^{\circ} \mathrm{C}\right)\end{array}$ & $100 \%$ degradation of QCT & [40] \\
\hline 9 & Strawberry juice & Storage in darkness $\left(56\right.$ days, $\left.4{ }^{\circ} \mathrm{C}\right)$ & $46.1 \%$ degradation of QCT & {$[6]$} \\
\hline 10 & Raspberry jams & Storage $\left(180\right.$ days, $\left.20^{\circ} \mathrm{C}\right)$ & $\begin{array}{l}\text { 40\% degradation of QCT 3- } \\
\text { glycoside }\end{array}$ & [50] \\
\hline
\end{tabular}

Table 4. Quality parameter of the proposed UPLC method for the determination of the QCT in foodstuffs.

\begin{tabular}{c|c|c|c|c} 
S.No & Conc $(\boldsymbol{\mu g} / \mathbf{L})$ & Area Counts & $\mathrm{R}^{2}$ & 0.9997 \\
\hline 1 & 10.00 & 65 & SE & 8.8211 \\
\hline 2 & 30.000 & 215 & SD of intercept & 10.116 \\
\hline 3 & 50.000 & 351 & LOD & 4.52 \\
\hline 4 & 100.000 & 730 & LOQ & 13.71
\end{tabular}

\section{Conclusions}

The stability of QCT being an abundant plant bioflavonoid with different health-related properties and its M-QCT complexes is an important analytical task. In this study, the complex 
of $\mathrm{Mg}^{2+}, \mathrm{Zn}^{2+}$ with QCT, was prepared and characterized. Their stability was checked under different $\mathrm{pH}$ conditions using UPLC coupled to a PDA detector. The present results conclude that QCT in garlic pickle was found in oxidized form, but in the non-processed fresh garlic, QCT was in its non-oxidized form. The oxidation could occur during processing of garlic pickle with low $\mathrm{pH}$ (with vinegar) that could modify the chemical structure of QCT, which is present in the garlic extract. Also, Zn-QCT was more lethal to the zebrafish embryo compare to MgQCT and std QCT. Hence, M-QCT could be used in processed foods and other items instead of pure QCT as a dietary supplement for flavonoid QCT. The methods illustrated for calculating ADIs use most of the obtainable toxicity data and offer a reliable approach in assessing health risks for lifetime exposure of toxicants; define NOELs considering several criticisms due to dose-response slopes and the number of animals tested. In the middle ages, these methods could be deliberated as an alternative to the current methods of establishing protection points for the toxic chemicals.

\section{Funding}

This research received no external funding.

\section{Acknowledgments}

The authors thank Vellore Institute of Technology, Vellore - 632014 for the financial support, working platform, and instrument facilities that are given to complete the study.

\section{Conflicts of Interest}

The authors declare no conflict of interest.

\section{References}

1. Bischoff, S.C. Quercetin: potentials in the prevention and therapy of disease. Current Opinion in Clinical Nutrition and Metabolic Care 2008, 11, 733-740, https://doi.org/10.1097/MCO.0b013e32831394b8.

2. Corradini, E.; Foglia, P.; Giansanti, P.; Gubbiotti, R.; Samperi, R.; Lagana, A. Flavonoids: chemical properties and analytical methodologies of identification and quantitation in foods and plants. Natural Product Research 2011, 25, 469-495, https://doi.org/ 10.1080/14786419.2010.482054.

3. Mullen, W.; Rouanet, J.M.; Auger, C.; Teissedre, P.L.; Caldwell, S.T.; Hartley, R.C.; Lean, M.E.; Edwards, C.A.; Crozier, A. Bioavailability of [2-14C] quercetin-4'-glucoside in rats. Journal of Agricultural and Food Chemistry 2008, 56, 12127-12137, https://doi.org/10.1021/jf802754s.

4. Grazul, M.; Budzisz, E. Biological activity of metal ions complexes of chromones, coumarins and flavones. Coordination Chemistry Reviews 2009, 253, 2588-2598, https://doi.org/10.1016/j.ccr.2009.06.015.

5. Chen, J.; Kang, J.H. Quercetin and trichostatin A cooperatively kill human leukemia cells. Die Pharmazie 2005, 60, 856-860, https://doi.org/10.3390/ijms17081354.

6. Odriozola-Serrano, I.; Soliva-Fortuny, R.; Martín-Belloso, O. Phenolic acids, flavonoids, vitamin C and antioxidant capacity of strawberry juices processed by high-intensity pulsed electric fields or heat treatments. European Food Research and Technology 2008, 228, https://doi.org/10.1007/s00217-008-0928-5.

7. Buchner, N.; Krumbein, A.; Rohn, S.; Kroh, L.W. Effect of thermal processing on the flavonols rutin and quercetin. Rapid Communications in Mass Spectrometry 2006, 20, 3229-3235, https://doi.org/10.1002/rcm.2720.

8. Dehghan, G.; Khoshkam, Z. Tin (II)-quercetin complex: Synthesis, spectral characterisation and antioxidant activity. Food Chemistry 2012, 131, 422-426, https://doi.org/10.1016/j.foodchem.2011.08.074.

9. Moon, Y.J.; Wang, L.; DiCenzo, R.; Morris, M.E. Quercetin pharmacokinetics in humans. Biopharmaceutics and Drug Disposition 2008, 29, 205-217, https://doi.org/10.1002/bdd.605.

10. Cai, X.; Fang, Z.; Dou, J.; Yu, A.; Zhai, G. Bioavailability of quercetin: problems and promises. Current Medicinal Chemistry 2013, 20, 2572-2582, https://doi.org/10.2174/09298673113209990120.

11. Priprem, A.; Watanatorn, J.; Sutthiparinyanont, S.; Phachonpai, W.; Muchimapura, S. Anxiety and cognitive effects of quercetin liposomes in rats. Nanomedicine: Nanotechnology, Biology and Medicine 2008, 4, 7078, https://doi.org/10.1016/j.nano.2007.12.001. 
12. Gao, L.; Liu, G.; Wang, X.; Liu, F.; Xu, Y.; Ma, J. Preparation of a chemically stable quercetin formulation using nanosuspension technology. International Journal of Pharmaceutics 2011, 404, 231-237, https://doi.org/10.1016/j.ijpharm.2010.11.009.

13. Joye, I.J.; Julian McClements, D. Biopolymer-based delivery systems: challenges and opportunities. Current $\begin{array}{lllll}\text { Topics in } & \text { Medicinal 1026-1039, }\end{array}$ https://doi.org/10.2174/1568026615666150825143130.

14. Wang, W.; Sun, C.; Mao, L.; Ma, P.; Liu, F.; Yang, J.; Gao, Y. The biological activities, chemical stability, metabolism and delivery systems of quercetin: A review. Trends in Food Science and Technology 2016, 56, 21-38, https://doi.org/10.1016/j.tifs.2016.07.004.

15. Chang-Bravo, L.; López-Córdoba, A.; Martino, M. Biopolymeric matrices made of carrageenan and corn starch for the antioxidant extracts delivery of Cuban red propolis and yerba mate. Reactive and Functional Polymers 2014, 85, 11-19, https://doi.org/10.1016/j.reactfunctpolym.2014.09.025.

16. Ensign, L.M.; Cone, R.; Hanes, J. Oral drug delivery with polymeric nanoparticles: the gastrointestinal mucus barriers. Advanced Drug Delivery Reviews 2012, 64, 557-570, https://doi.org/10.1016/j.addr.2011.12.009.

17. Jeon, S.; Yoo, C.Y.; Park, S.N. Improved stability and skin permeability of sodium hyaluronate-chitosan multilayered liposomes by Layer-by-Layer electrostatic deposition for quercetin delivery. Colloids and Surfaces B: Biointerfaces 2015, 129, 7-14, https://doi.org/10.1016/j.colsurfb.2015.03.018.

18. Lu, W.; Kelly, A.L.; Miao, S. Emulsion-based encapsulation and delivery systems for polyphenols. Trends in Food Science and Technology 2016, 47, 1-9, https://doi.org/10.1016/j.tifs.2015.10.015.

19. Song, S.; Chen, F.; Xing, X.; Ren, M.; Ma, Q.; Xie, Y.; Tang, Q.; Luo, J. Concurrent quantification and comparative pharmacokinetic analysis of bioactive compounds in the Herba Ephedrae-Semen Armeniacae Amarum herb pair. Journal of Pharmaceutical and Biomedical Analysis 2015, 109, 67-73, https://doi.org/10.1016/j.jpba.2015.02.004.

20. Matos, M.; Gutiérrez, G.; Coca, J.; Pazos, C. Preparation of water-in-oil-in-water (W1/O/W2) double emulsions containing trans-resveratrol. Colloids and Surfaces A: Physicochemical and Engineering Aspects 2014, 442, 69-79, https://doi.org/10.1016/j.colsurfa.2013.05.065.

21. Singh, R.; Tiwari, S.; Tawaniya, J. Review on nanotechnology with several aspects. International Journal of Research in Computer Engineering and Electronics 2013, 2, 1-8, https://doi.org/10.1155/2014/843687.

22. Murugan, N.; Natarajan, D. Bionanomedicine for antimicrobial therapy - a case study from Glycosmis pentaphylla plant mediated silver nanoparticles for control of multidrug resistant bacteria. Letters in Applied NanoBioScience 2018, 8, 523-540.

23. Santhanamariammal, C.; Raja Sekharan, T.; Lydia, B.; Ramkumar, P. Formulation and evaluation of Prednisolone retention enema as dispersible tablet and vehicle for the treatment of ulcerative colitis. Letters in Applied NanoBioScience 2019, 8, 545-552.

24. Otuechere, C.A.; Durugbo, E.U.; Adesanya, O.; Omotolani, F.O.; Osho, A. Essential oil of Alchornea laxiflora (benth): phytochemical, antimicrobial and toxicity evaluations. Letters in Applied NanoBioScience 2019, 8, 661-665, https://doi.org/10.33263/LIANBS83.661665.

25. Agarwal, H.; Malviya, R.; Sharma, P.K. Evaluation of in situ gel forming system loaded with etoricoxib and herbal adjuvant nanoparticles against human colon cancer cell lines (HT-29). Letters in Applied NanoBioScience 2020, 9, 789-795, https://doi.org/10.33263/LIANBS0091.789795.

26. Khani, R.; Sheykhi, R.; Bagherzade, G. An environmentally friendly method based on micro-cloud point extraction for determination of trace amount of quercetin in food and fruit juice samples. Food Chemistry 2019, 293, 220-225, https://doi.org/10.1016/j.foodchem.2019.04.099.

27. Zhu, Y.; Yu, J.; Jiao, C.; Tong, J.; Zhang, L.; Chang, Y.; Sun, W.; Jin, Q.; Cai, Y. Optimization of quercetin extraction method in Dendrobium officinale by response surface methodology. Heliyon 2019, 5, 2374, https://doi.org/10.1016/j.heliyon.2019.e02374.

28. Kim, S.W.; Ko, M.J.; Chung, M.S. Extraction of the flavonol quercetin from onion waste by combined treatment with intense pulsed light and subcritical water extraction. Journal of Cleaner Production 2019, 231, 1192-1199, https://doi.org/10.1016/j.jclepro.2019.05.280.

29. Careri, M.; Corradini, C.; Elviri, L.; Nicoletti, I.; Zagnoni, I. Direct HPLC analysis of quercetin and transresveratrol in red wine, grape, and winemaking byproducts. Journal of Agricultural and Food Chemistry 2003, 51, 5226-5231, https://doi.org/10.1021/jf034149g.

30. Ghosh, N.; Chakraborty, T.; Mallick, S.; Mana, S.; Singha, D.; Ghosh, B.; Roy, S. Synthesis, characterization and study of antioxidant activity of quercetin-magnesium complex. Spectrochimica Acta Part A: Molecular and Biomolecular Spectroscopy 2015, 151, 807-813, https://doi.org/10.1016/j.saa.2015.07.050.

31. Ghosh, N.; Sandur, R.; Ghosh, D.; Roy, S.; Janadri, S. Acute, 28 days sub acute and genotoxic profiling of Quercetin-Magnesium complex in Swiss albino mice. Biomedicine and Pharmacotherapy 2017, 86, 279291, https://doi.org/10.1016/j.biopha.2016.12.015.

32. Mathiyalagan, S.; Mandal, B.K. Preparation of metal doped quercetin nanoparticles, characterization and their stability study. Letters in Applied NanoBioScience 2019, 8, 704-710. 
33. Bukhari, S.B.; Memon, S.; Tahir, M.M.; Bhanger, M. Synthesis, characterization and investigation of antioxidant activity of cobalt-quercetin complex. Journal of Molecular Structure 2008, 892, 39-46, https://doi.org/10.1016/j.saa.2008.07.030.

34. Zhang, C.; Korshin, G.V.; Kuznetsov, A.M.; Yan, M. Experimental and quantum-chemical study of differential absorbance spectra of environmentally relevant species: A study of quercetin deprotonation and its interactions with copper (II) ions. Science of The Total Environment 2019, 679, 229-236, https://doi.org/10.1016/j.scitotenv.2019.04.370.

35. Alugoju, P.; Narsimulu, D.; Bhanu, J.U.; Satyanarayana, N.; Periyasamy, L. Role of quercetin and caloric restriction on the biomolecular composition of aged rat cerebral cortex: An FTIR study. Spectrochimica Acta Part A: Molecular and Biomolecular Spectroscopy 2019, 220, 117-128, https://doi.org/10.1016/j.saa.2019.05.033.

36. Lakshmi, B.A.; Bae, J.-Y.; An, J.H.; Kim, S. Facile design and spectroscopic characterization of novel bioinspired Quercetin-conjugated tetrakis (dimethylsulfoxide) dichlororuthenium (II) complex for enhanced anticancer properties. Inorganica Chimica Acta 2019, 495, https://doi.org/10.1021/cr400460s.

37. Cakar, S.; Özacar, M. The effect of iron complexes of quercetin on dye-sensitized solar cell efficiency. Journal of Photochemistry and Photobiology A: Chemistry 2017, 346, 512-522, https://dx.doi.org/10.1016/j.jphotochem.2017.07.006.

38. Yılmaz, D.Ç.; Pekin, M. Potentiometric and Chromatographic Study of Cu (II) and Al (III) Complexes of Quercetin. Marmara Pharmaceutical Journal 2017, 21, 330-337, https://doi.org/10.12991/mpj.32903.

39. Elosta, A.; Slevin, M.; Rahman, K.; Ahmed, N. Aged garlic has more potent antiglycation and antioxidant properties compared to fresh garlic extract in vitro. Scientific Reports 2017, 7, https://doi.org/10.1038/srep39613.

40. Chen, X.; McClements, D.J.; Zhu, Y.; Chen, Y.; Zou, L.; Liu, W.; Cheng, C.; Fu, D.; Liu, C. Enhancement of the solubility, stability and bioaccessibility of quercetin using protein- based excipient emulsions. Food Research International 2018, 114, 30-37, https://doi.org/10.1016/j.foodres.2018.07.062.

41. Lin, S.; Zhao, Y.; Xia, T.; Meng, H.; Ji, Z.; Liu, R.; George, S.; Xiong, S.; Wang, X.; Zhang, H. High content screening in zebrafish speeds up hazard ranking of transition metal oxide nanoparticles. ACS Nano 2011, 5, 7284-7295, https://doi.org/10.1021/nn202116p.

42. Bai, W.; Tian, W.; Zhang, Z.; He, X.; Ma, Y.; Liu, N.; Chai, Z. Effects of copper nanoparticles on the development of zebrafish embryos. Journal of Nanoscience and Nanotechnology 2010, 10, 8670-8676, https://doi.org/10.1166/jnn.2010.2686.

43. Lee, K.J.; Browning, L.M.; Nallathamby, P.D.; Desai, T.; Cherukuri, P.K.; Xu, X.H.N. In vivo quantitative study of sized-dependent transport and toxicity of single silver nanoparticles using zebrafish embryos. Chemical Research in Toxicology 2012, 25, 1029-1046, https://doi.org/10.1021/tx300021u.

44. Price, K.R.; Bacon, J.R.; Rhodes, M.J. Effect of storage and domestic processing on the content and composition of flavonol glucosides in onion (Allium cepa). Journal of Agricultural and Food Chemistry 1997, 45, 938-942, https://doi.org/10.1021/jf9605916.

45. Ranilla, L.G.; Genovese, M.I.; Lajolo, F.M. Effect of different cooking conditions on phenolic compounds and antioxidant capacity of some selected Brazilian bean (Phaseolus vulgaris L.) cultivars. Journal of Agricultural and Food Chemistry 2009, 57, 5734-5742, https://doi.org/10.1021/jf900527v.

46. Makris, D.P.; Rossiter, J.T. Heat-induced, metal-catalyzed oxidative degradation of quercetin and rutin (quercetin 3-O-rhamnosylglucoside) in aqueous model systems. Journal of Agricultural and Food Chemistry 2000, 48, 3830-3838, https://doi.org/10.1021/jf0001280.

47. Makris, D.P.; Rossiter, J.T. Domestic processing of onion bulbs (Allium cepa) and asparagus spears (Asparagus officinalis): Effect on flavonol content and antioxidant status. Journal of Agricultural and Food Chemistry 2001, 49, 3216-3222, https://doi.org/10.1021/jf001497z.

48. Igual, M.; García-Martínez, E.; Camacho, M.M.; Martínez-Navarrete, N. Changes in flavonoid content of grapefruit juice caused by thermal treatment and storage, Innovative Food Science \& Emerging Technologies 2011, 12, 153-162, https://doi.org/10.1016/j.ifset.2010.12.010.

49. Pekal, A.; Biesaga, M.; Pyrzynska, K. Interaction of quercetin with copper ions: Complexation, oxidation and reactivity towards radicals. Biometals 2011, 24, 41-49, https://doi.org/10.1007/s10534-010-9372-7.

50. Zafrilla, P.; Ferreres, F.; Tomas-Barberan, F.A. Effect of processing and storage on the antioxidant ellagic acid derivatives and flavonoids of red raspberry (Rubus idaeus) jams. Journal of Agricultural and Food Chemistry 2001, 49, 3651-3655, https://doi.org/10.1021/jf010192x. 


\section{Supplementary files}

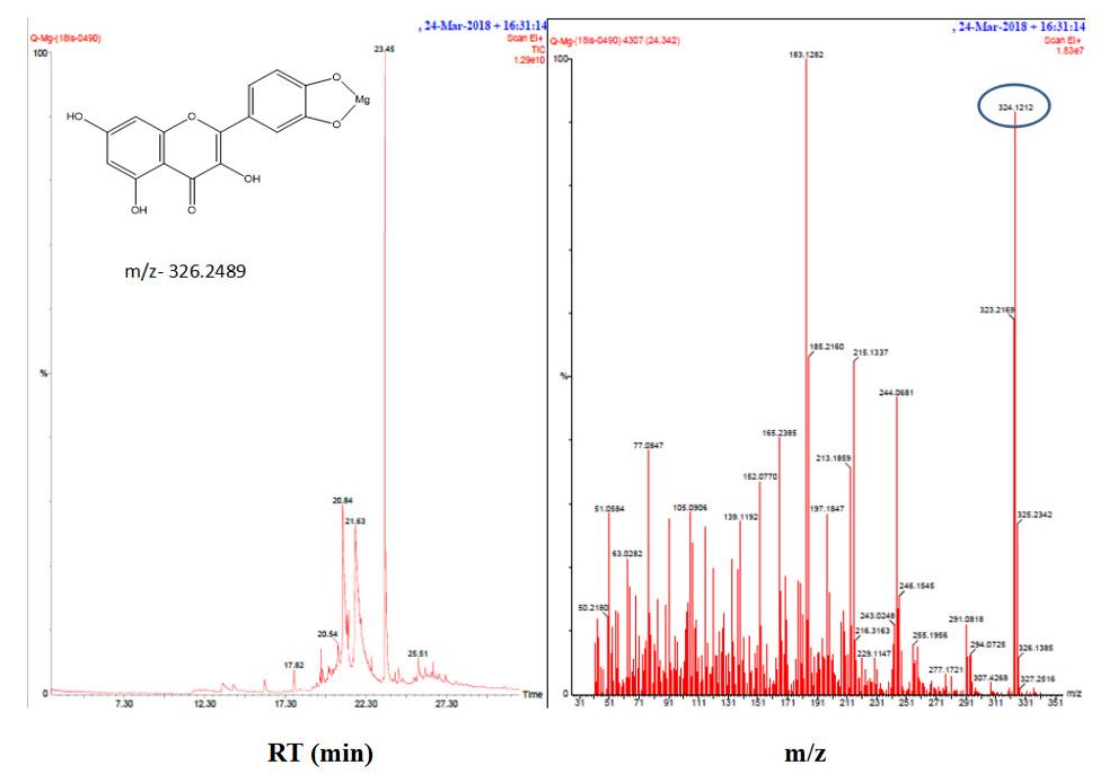

Figure S1. GC-MS spectrum of Mg-QCT complex.

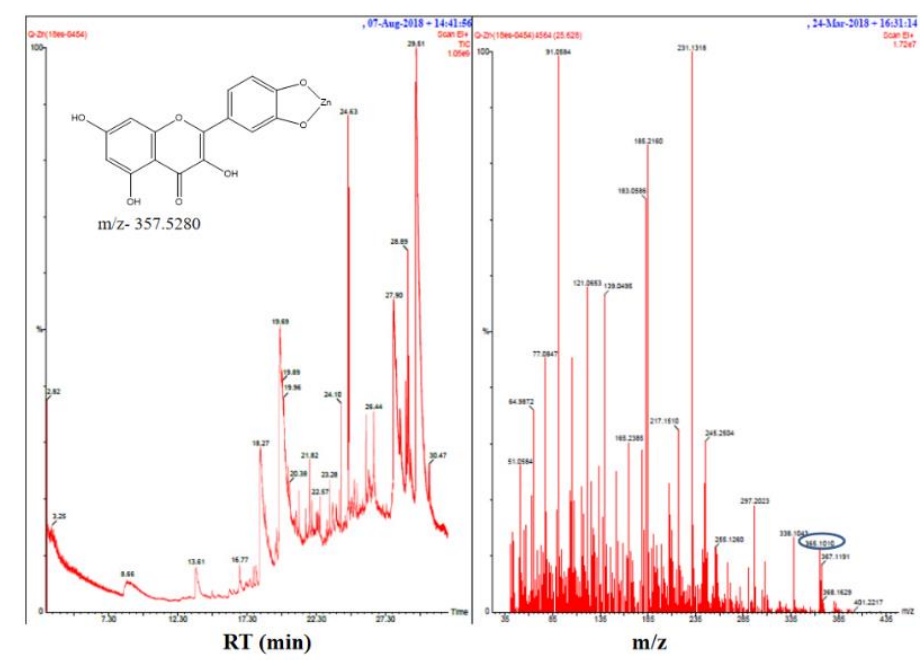

Figure S2. GC-MS spectrum of Zn-QCT complex.

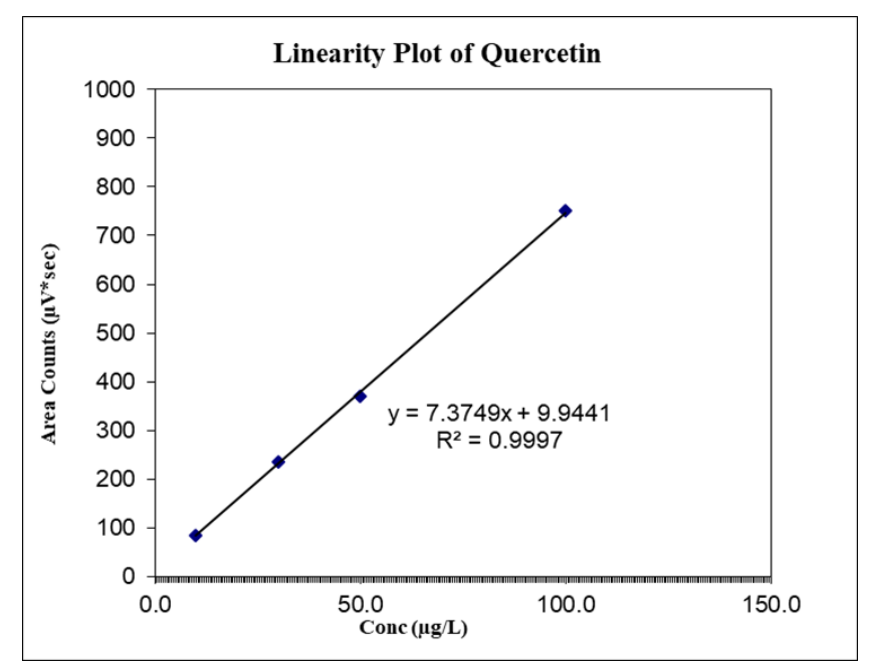

Figure S3. Linearity plot of QCT (concentration of QCT Vs UPLCArea counts). 